\begin{tabular}{|l|l|l|}
\hline & \\
PUCRS & HUMANIDADES & $\begin{array}{l}\text { Educação por escrito, Porto Alegre, v. 11, n. 1, p. 1-14, jan.-jun. } 2020 \\
\text { e-ISSN: 2179-8435 }\end{array}$ \\
\hline dif $h$ http://dx.doi.org/10.15448/2179-8435.2020.1.33195 & \\
\hline
\end{tabular}

SEÇÃO: ARTIGOS

\title{
Trilhando caminhos na revisão de literatura sobre a ética na pesquisa em educação
}

Treading paths in the literature review of ethics in academic master's research in education

\section{Hamilton Perninck \\ Vieira ${ }^{1}$ \\ orcid.org/0000-0003-0538-7796 \\ hpv_@hotmail.com}

\section{Jacques Therrien ${ }^{1}$}

orcid.org/0000-0001-5458-365X

jacques@ufc.br

\section{Wendel Alves de \\ Medeiros $^{1}$ \\ orcid.org/0000-0003-3422-6377 \\ wendeldesign@gmail.com}

Recebido em: 29 jan. 2019

Aprovado em: 8 jan. 2020.

Publicado em: 27 jul. 2020.

\section{(c) (i)}

Artigo está licenciado sob forma de uma licença Creative Commons Atribuição 4.0 Internacional.
Resumo: O estudo "Trilhando caminhos na revisão de literatura sobre a ética na pesquisa em educação" objetiva fazer uma revisão de literatura das dissertações de mestrado dos últimos três anos do repositório do Programa de Pós-Graduação em Educação da Universidade Estadual do Ceará (PPGE/UECE) para verificar como se deu o tratamento da ética nessas pesquisas, com vistas a promover reflexões sobre a formação ética em pesquisa na pós-graduação stricto sensu. A pergunta de pesquisa é: como as dissertações de mestrado em educação vêm desenvolvendo a ética na pesquisa científica no âmbito da universidade? A metodologia adotada é a pesquisa bibliográfica e a análise documental. A análise de dados foi elaborada na perspectiva do paradigma da teoria crítica. Das dissertações do PPGE/UECE a pesquisa fomentou discussões para certo cuidado com a dignidade e respeito aos seres humanos (60\%), com a liberdade de desistência a qualquer momento da pesquisa (30\%) e com o uso do Termo de Consentimento Livre e Esclarecido (TCLE) (37\%), mas com lacunas na apresentação clara dos riscos (16\%) e, também, no que diz respeito aos beneficios da pesquisa para o sujeito e para a área que está sendo investigada (6\%).

Palavras-chave: Revisão de literatura. Ética. Dissertação de mestrado.

Abstract: The study "Treading paths in the literature review of ethics in academic master's research in education" aims to make a literature review of master's theses of the past three years the State University of Ceará (UECE) to see how the treatment of ethics in these studies, with a view to point reflections on the ethical training in research in stricto sensu graduate. The research question is: How do the master's research in education has been developing ethics in scientific research at the university? The methodology is the literature search and document analysis. The data analysis was prepared in the paradigm perspective of critical theory. Dissertations of PPGE / UECE research pointed to a certain care with dignity and respect human (60\%), the freedom to withdraw at any time of the survey (30\%), the use of IC (37\%) but with gaps clear presentation of risks (16\%), especially the benefits of research to the subject and the area being investigated (6\%).

Keywords: Literature review. Ethic. Masters dissertation.

\section{Introdução}

O homem tornou-se capaz de perceber a sua existência e os caminhos para a sobrevivência da espécie no bojo do trabalho braçal e/ou intelectual, desde que fez a travessia da hominização para a humanização por meio da linguagem. Nesse sentido, "[...] compreender o ser humano significa compreender seus relacionamentos, captar a estrutura do movimento no qual o homem se gera a si mesmo, isto é, compreender a história, como a dimensão mais radical da vida" (OLIVEIRA, 1997, p. 12). 
Os relacionamentos humanos e a estrutura do modo de produção de uma sociedade em contexto configuram o modus vivendi e a trajetória de vida de cada sujeito histórico nas trilhas da história da humanidade. O homem na busca pela sobrevivência desbrava possibilidades, enveredase pelo desconhecido e caminha na direção de modificar a natureza na tentativa de conhecer suas origens e suas perspectivas de futuro. Assim, o homem, enquanto extensão da natureza, também se distingue dela pelo estranhamento, exercendo o seu poder sobre ela, produzindo a cultura, o saber e o conhecimento. Diante disso,

[...] o compromisso com a existência, o sentir-se não simplesmente o reflexo de uma harmonia natural (o homem inserido no cosmos), para o homem 'histórico', isto é engajado no processo de sua própria gênese, numa comunidade em comunicação, mediada pelo relacionamento com a natureza (OLIVEIRA, 1997, p. 13).

A historicidade do homem marca sua presença no mundo enquanto ser de horizonte, não meramente para se adaptar, mas para transformar o mundo à medida que transforma a si mesmo. Portanto,

[...] mais do que um ser no mundo, o ser humano se tornou Presença no mundo, com o mundo e com os outros. [...] Na verdade, seria incompreensivel se a consciência de minha presença no mundo não significasse já a impossibilidade de minha ausência na construção da própria presença (FREIRE, 1996, p. 18-19).

Em uma compreensão baconiana, "saber é poder"! Dessa forma, "a natureza compreendida e dominada pela ciência, surge de novo no aparelho de produção e de destruição, que mantem e melhora a vida dos indivíduos e, ao mesmo tempo, os submete aos senhores do aparelho" (HABERMAS, 1968, p. 51). Portanto, o saber científico produzido como fruto da curiosidade da presença humana no mundo em busca da liberdade é ao mesmo tempo um elemento escravizante desse devir.

Sendo assim, não há possibilidade de separação entre pesquisa, ciência, ideologia, política e ética. Entende-se que "o conhecimento que produzo será usado por alguém num projeto específico de controle e manipulação [...]. Mas a manipulação se tornará tanto mais dificil quanto mais consciente ele estiver de sua condição de cientista passivel de ser manipulado" (ALVES, 2000, p. 101). A produção científica é uma atividade político-ideológica dos sujeitos cognoscentes que desejam compreender o objeto cognoscivel a favor de alguém ou contra alguém. Não existe ciência descolada da teoria, do método, da política e da ética que a constituem.

Nessa direção, este artigo tem uma inquietação que se traduz com o seguinte problema de investigação: como as pesquisas de mestrado em educação vêm desenvolvendo a ética na pesquisa científica no âmbito da universidade? Assim, tem-se como objetivo fazer uma revisão de literatura das dissertações do Programa de Pós-Graduação em Educação da Universidade Estadual do Ceará (PPGE/UECE) para verificar como se dá o tratamento ético nessas pesquisas, com vistas a apontar reflexões sobre a formação ética em pesquisa na pós-graduação stricto sensu. Para tanto, o projeto de reflexão do presente trabalho está organizado da seguinte forma: a) mapeamento dos referenciais teóricos; b) postulação dos aspectos teórico-metodológicos; c) reflexões em torno das análises de dados e dos achados de pesquisa; e d) considerações finais.

\section{Referenciais teóricos}

Ao se tratar do conhecimento culturalmente acumulado pela humanidade, à universidade foi dado o papel de transmitir e de recriar o saber científico. Assim, a academia tem uma triplice missão segundo a legislação: ensino, pesquisa e extensão (BRASIL, 1996, art. 43, VII; art. 52, III). De um lado, ela deve tornar conhecidos os saberes científicos já desenvolvidos na história das civilizações desde os primórdios até os dias de hoje: o ensino.

De outro lado, o conhecimento é dinâmico e, por isso, além de saber melhor o que já se sabe, é preciso aprender o que se ignora: aqui reside a pesquisa acadêmica. No entanto, o ensino e a pesquisa precisam chegar à população de forma compreensivel a fim de melhorar a qualidade de vida das pessoas, por isso, a extensão. Portanto, "a universidade é o lugar do pensamento, não só 
pela lógica da determinação, do conhecimento como valores absolutos, mas também pela lógica da relação com o bem-estar do ser humano e da sociedade" (GOERGEN, 2015, p. 308).

A ciência é a busca pela verdade provisória através da correção de erros sucessiveis. Dessa forma, a construção do conhecimento científico é propriamente o método em ação que permite ao pesquisador observar um fato delimitado e visualizado pelas lentes da teoria a fim de construir o conceito. O fato em si não é puro, pois a delimitação, a seleção, a análise e as proposições da pesquisa são definidas por uma pré-teoria. 0 objeto não fala por si. É o sujeito que o observa, quem lhe dá voz e significados. Em suma, todo construto teórico da pesquisa é densamente marcado pela biografia do pesquisador e/ou pelos interesses do mercado (ALVES, 2000):

De fato, vivemos hoje numa época de fetichização do conhecimento científico e da técnica. Um dos aspectos mais graves dessa problemática, especialmente na universidade, é a subordinação da ciência e tecnologia aos interesses econômicos e mercadológicos (GOERGEN, 2015, p. 306-307).

Neste sentido, faz-se necessária a reflexão sobre a ética na pesquisa. Compreendendo a ética como uma reflexão sobre a moral e, no caso, uma suposta "moral da ciência", é crucial assinalar que a ciência busca responder o quê? e não para que o conhecimento. O trato ético da pesquisa não reside na ciência e na tecnologia produzidas, está para além delas. Em síntese, "[...] a ciência não pode oferecer critérios objetivos para decidir a respeito da desejabilidade ou não, do ponto de vista humano, de seus fins. Isto significa que as questões éticas extrapolam o alcance das decisões e explicações técnicocientíficas" (GOERGEN, 2015, p. 311).

A regulação da ética em pesquisa no Brasil encontra uma primeira iniciativa na resolução $n{ }^{\circ}$ $1 / 88$ do Conselho Nacional de Saúde (LA FARE; MACHADO; CARVALHO, 2014). Oito anos mais tarde, verifica-se que:

A Resolução n 196/96 instaurou as diretrizes para a criação da Comissão Nacional de Ética em Pesquisa (CONEP) e de Conselhos de

\begin{abstract}
Ética em Pesquisa com Seres Humanos (CEP), formando o que se convencionou chamar de sistema CEP/CONEP, responsável pela regulação da ética em pesquisa com seres humanos em todo Brasil. Embora essa resolução tenha sido construida por um Grupo de Trabalho que consultou pesquisadores de todo o Brasil, desde o início, esteve claro a importância do aprimoramento constante desse sistema (LA FARE; MACHADO; CARVALHO, 2014, p. 258).
\end{abstract}

O CEP/CONEP foi instaurado no âmbito das pesquisas na área da saúde. Não havia um código de ética em pesquisa que tratasse da especificidade das áreas, sobretudo, da área da educação que é o objeto dessa investigação. Segundo Severino (2002, p. 181), nessa resolução a eticidade da pesquisa implica os seguintes quesitos: autonomia (consentimento, proteção e dignidade dos sujeitos); beneficência (ponderação entre riscos e benefícios da pesquisa); não maleficência (garantia que os danos previsiveis sejam evitados); justiça; e equidade (relevância social). Progredindo nesses principios, vinte anos depois a Resolução n. ${ }^{\circ}$ 510/2016 propõe que,

[...] as Ciências Humanas e Sociais têm especificidades nas suas concepções e práticas de pesquisa, na medida em que nelas prevalece uma acepção pluralista de ciência da qual decorre a adoção de múltiplas perspectivas teórico-metodológicas, bem como lidam com atribuições de significado, práticas e representações, sem intervenção direta no corpo humano, com natureza e grau de risco específico (BRASIL, 2016).

Diante disso, por conta da pluralidade de teorias e de práticas de pesquisas, foi necessária uma resolução que contemplasse a realidade multirreferencial e multifacetada da pesquisa na área das Ciências Humanas e Sociais, sobretudo, na área de Educação. Dessa forma, a "[... ética em pesquisa implica o respeito pela dignidade humana e a proteção devida aos participantes das pesquisas científicas envolvendo seres humanos" (BRASIL, 2016). Em suma, "a vontade moral que deve nortear a atividade de pesquisa se encontra, portanto, na relação entre o direito particular (no caso da ciência) e o direito público (no caso da sociedade). Esta relação se traduz pelos conceitos de compromisso e responsabilidade" (GOERGEN, 2015, p. 312).

Pensando nessa construção do conhecimento 
na universidade sob o prisma da ética, faz-se necessária a reflexão de como isso vem sendo tratado nas dissertações de mestrado em nossos dias. Entendendo que a dissertação "trata-se da comunicação dos resultados de uma pesquisa e de uma reflexão, que versa sobre um tema igualmente único e delimitado" (SEVERINO, 2002, p. 151). Esse autor ainda diz que a pesquisa de mestrado é um trabalho científico pessoal, orientado e vinculado a uma fase de iniciação à ciência, seguindo a mesma lógica de uma tese de doutorado, não sendo, contudo, exigido o mesmo grau de originalidade que essa reivindica.

Apesar de ser um trabalho de iniciação à pesquisa, é fundamental que o mestrando leve em consideração as questões éticas no processo de produção do conhecimento. Em suma, entendese que a ética, nas dissertações de mestrado, precisa dialogar sobre a integridade da pesquisa (plágio e autoplágio), princípios, aspectos legais oriundos dos comitês e o trato com a autonomia dos sujeitos no tocante aos riscos e beneficios da pesquisa (LAFARE; MACHADO; CARVALHO, 2014).

\section{Aspectos teórico-metodológicos}

Segundo Creswell (2010, p. 116), "as práticas éticas envolvem muito mais do que apenas seguir um conjunto de diretrizes estáticas, como aquelas proporcionadas pelas associações profissionais" e isso implica que o pesquisador deve internalizar o ser ético antes, durante e depois da pesquisa, afinal, no que concerne às áreas da Saúde e das Ciências Humanas e Sociais, os quesitos ligados à proteção e à dignidade dos sujeitos, à ponderação entre os riscos e os benefícios da pesquisa, à garantia que os danos previsiveis sejam evitados e justiça e equidade refletem a complexidade dos problemas de pesquisas que envolvem a dimensão humana.

Nesse aspecto, Creswell (2010) vai apontar que em todas as fases da pesquisa podem surgir dilemas éticos. A seguir, pontuaremos os procedimentos éticos que são passiveis de identificação no repositório de dissertações do Programa de Pós-Graduação em Educação da Universidade Estadual do Ceará (PPGE/UECE), no recorte temporal de 2013 a 2015. Questões ou procedimentos éticos podem ocorrer durante a elaboração do problema de pesquisa, tanto que Punch (2005) apud Creswell (2010, p. 117) afirmam que "é importante identificar um problema que beneficie os indivíduos que estão sendo estudados, um problema que será significativo para outras pessoas além do pesquisador".

Neste artigo, trabalhamos como metodologia e como procedimentos de coleta de dados, respectivamente, a pesquisa bibliográfica e a análise documental, na perspectiva do paradigma da teoria crítica para a análise dos dados por meio de nossa fundamentação teórica. O paradigma de pesquisa neste artigo é entendido na perspectiva de Guba e Lincoln (1994) como um sistema de crenças que fundamentam os princípios de compreensão do mundo, do homem e de suas relações com o local onde vive em sociedade.

Fundamentalmente, existem segundo esses autores (1994) quatro paradigmas de pesquisa: o positivismo, o pós-positivismo, a teoria crítica e o construtivismo, também chamado de naturalismo. Adotamos como paradigma a teoria crítica, pois essa permite um processo de reflexão e de desvelamento acerca dos estrangulamentos sociais oriundos do Capital, que alcançam as relações humanas e reverberam nas racionalidades que configuram a pesquisa cientifica (ALVES, 2000; BOUFLEUER, 2001; FREIRE, 1996, HABERMAS, 1968, SAVIANI, 2010).

Como procedimentos de coleta de dados, concebemos que,

A pesquisa documental é muito próxima da pes-
quisa bibliográfica. O elemento diferenciador está
na natureza das fontes: a pesquisa bibliográfica
remete para as contribuições de diferentes au-
tores sobre o tema, atentando para as fontes
secundárias, enquanto a pesquisa documental
recorre a materiais que ainda não receberam
tratamento analítico, ou seja, as fontes primárias
(SÁ-SILVA et. al., 2009, p. 6, grifo nosso).

As dissertações fazem parte do material biográfico secundário e a legislação sobre a ética será o material primário não tratado (Resoluções n. ${ }^{\circ}$ 196/96 e n. ${ }^{\circ}$ 510/2016). O movimento é perceber as convergências e as divergências das pesquisas de mestrado em seu confronto com a legislação ética de pesquisa. 
Creswell (2010) continua a argumentar insistindo que os objetivos ou as questões fundamentais de qualquer estudo precisam ser descritos para os participantes envolvidos, já em relação à coleta de dados alguns pontos gerais precisam ser destacados: 1) respeito ao local e aos participantes; 2) faz-se importante submeter a pesquisa ao que esse autor (2010, p. 118) chama de "Conselho de Revisão Institucional (Institutional Review Board - IRB) [...] Os comitês de IRB existem nos campi devido às regulamentações federais que protegem contra violações dos direitos humanos", aqui implica o conselho avaliar os diferentes tipos de danos possiveis de acontecerem com seres humanos.

No Brasil, chamamos de Comitês de Ética e, quanto ao consentimento de informação, os pesquisadores podem dispor de modelos e de formulários específicos para protegerem seus participantes no momento da coleta de dados. Há de se ressaltar a importância da confidencialidade desejada por alguns participantes, momento em que os pesquisadores de pronto precisam atender a esse tipo de solicitação, levando em consideração que os colaboradores em pesquisas devem também estar cientes dos riscos de optarem pela não confidencialidade.

Por meio da pesquisa bibliográfica foi possivel fazer uma revisão de literatura sobre como vem sendo tratados os procedimentos éticos nas pesquisas de mestrado. Neste sentido, "[...] a revisão de bibliografia deve estar a serviço do problema de pesquisa [...]" (ALVES, 1992, p. 53) A revisão de literatura ajuda a definir o objeto de estudo e teorias, evitando que o pesquisador invente a roda. É um "trabalho de garimpagem" (ALVES, 1992, p. 54) na direção de compreender as nuanças de um objeto que já vem sendo estudado ao longo do tempo.
Mediante essas compreensões, nosso movimento foi o de perceber como se deu o tratamento ético nas produções das dissertações de mestrado. Neste sentido, os procedimentos de buscas dos textos no repositório da UECE, no recorte temporal de 2013 a 2015, giraram em torno da verificação nos resumos e nos capítulos metodológicos dos seguintes elementos éticos da pesquisa: (1) princípios de dignidade e respeito aos seres humanos, sobretudo, no que tange à privacidade e ao anonimato dos sujeitos; (2) autonomia dos sujeitos relativos à liberdade de desistência da pesquisa a qualquer hora; e (3) aspectos legais que envessem os benefícios, os riscos da pesquisa e o uso do Termo de Consentimento Livre e Esclarecido (TCLE).

\section{Análise de dados}

Para dar conta da intepretação dos dados da pesquisa, faremos uma reflexão geral dos achados, através de uma análise das dissertações organizadas por ano de defesa. O primeiro momento é geral e o segundo momento será de detalhamento das pesquisas defendidas em 2013, 2014 e 2015, respectivamente.

De forma global, realizamos a análise de 76 dissertações de mestrado. Durante a análise dos trabalhos de mestrado do PPGE/UECE ficou evidente certo cuidado com a dignidade e respeito aos seres humanos (46 trabalhos, $60 \%$ ), com a liberdade de desistência a qualquer momento da pesquisa (23 trabalhos, 30\%), com o uso do TCLE (28 trabalhos, 37\%), mas com lacunas na apresentação clara dos riscos (12 trabalhos, $16 \%$ ) e também no que diz respeito aos benefícios da pesquisa para o sujeito e para a área que está sendo investigada (5 trabalhos, 6\%). Essas constatações partem da análise do Quadro 1. 
Quadro 1 - A ética nas pesquisas de mestrado em educação da UECE

\begin{tabular}{lllllll}
\hline Dissertações & Principios & Autonomia & Aspectos legais \\
\hline Ano & Quantidade & $\begin{array}{l}\text { Dignidade e respeito aos } \\
\text { seres humanos }\end{array}$ & Liberdade & Benefícios & Riscos & TCLE \\
\hline 2013 & 24 & 10 & 4 & 2 & 3 & 8 \\
2013 & 26 & $19^{3}$ & 08 & 1 & 07 & 07 \\
2015 & 26 & 17 & 11 & 2 & 2 & 13 \\
TOTAL & 76 & 46 & 23 & 5 & 12 & 28 \\
\hline
\end{tabular}

Fonte: Elaboração pelos autores com base no banco de dados do PPGE/UECE nas dissertações defendidas entre 2013 e 2015

Dentre as 24 dissertações de 2013, somente 12 (50\%) apresentaram alguma mínima preocupação com a ética em pesquisa, considerando os três itens de análise que elencamos neste artigo. No entanto, somente duas fizeram um voo mais além dentro das questões éticas alvo de nossa análise conforme o Quadro 1, sendo que uma deixou de tratar da liberdade de desistência (ROCHA, S., 2013) e a outra não apresentou os benefícios da pesquisa (REIS, 2013).

No ano de 2014, mediante a análise das 26 dissertações, 19 trabalhos (73\%) destacam uma preocupação com a questão do anonimato e, consequentemente, com a dignidade dos sujeitos envolvidos, no entanto, desse número, 2 estudos (10\%) expõem claramente o nome de seus lócus de investigação. No quesito autonomia, 8 trabalhos (31\%) preocupam-se em deixar de forma tácita que os sujeitos têm liberdade para desistir de suas participações nas pesquisas a qualquer momento. $\mathrm{O}$ quadro denuncia que no tocante aos aspectos legais, apenas 1 trabalho (4\%) deixa claro quais são os benefícios que suas pesquisas podem proporcionar aos envolvidos. Já em relação aos riscos, mesmo que seus trabalhos não ofereçam danos significativos, apenas 7 estudos (27\%) preocuparam-se em expor esse item aos envolvidos. No que diz respeito ao TCLE, 7 trabalhos (27\%) valeram-se desse importantíssimo instrumento ao utilizá-lo e ao anexá-lo de fato ao relatório final da pesquisa.

Ao todo, os procedimentos éticos adotados nas dissertações de mestrado do PPGE/UECE do ano de 2014 apontam que as pesquisas que envolveram sujeitos preservaram o anonimato, porém muitos não anexaram o TCLE. Outro achado interessante tem relação com a questão dos beneficios: poucos esclarecem quais seriam os ganhos para a pesquisa e para os entrevistados. Consideramos isso relevante, pois entendemos ser pertinente a devolutiva dos resultados da pesquisa à comunidade. A sensação que fica é que os pesquisadores se inserem nos lócus de pesquisa e depois se esquecem de relatar o que aconteceu e quais são as impressões e/ou os impactos sociais daquilo que se propuseram a investigar.

No ano de 2015, de um total de 26 trabalhos, 17 (65\%) verificam a dignidade e respeito aos seres humanos quanto ao anonimato e à privacidade. Refletindo sobre o Quadro 1, 13 dissertações (50\%) utilizam o TCLE, e 11 pesquisas (42\%) possibilitam aos sujeitos o direito de desistir da pesquisa a qualquer momento. As grandes lacunas ficam a cargo da apresentação dos riscos (8\%) e dos benefícios (8\%) da pesquisa, já que, entre todos os trabalhos observados, somente 2 contemplaram esses critérios. 


\subsection{As dissertações defendidas no ano de 2013}

Dentre as dissertações de 2013, verificamos que existem 6 (25\%) estudos teóricos sem preocupação com a ética. É natural que para eles não houvesse preocupação com a ética da pesquisa com seres humanos (ARAÚJO, 2013; LIMA, 2013; BERNARDO, 2013; BEZERRA, 2013; CUNHA, 2013; RIBEIRO, 2013). Das 10 dissertações (42\%) que apresentam certo cuidado com a ética, a grande ênfase está na dignidade e no respeito aos seres humanos e no uso do TCLE. Selecionamos a seguir trechos de trabalhos representativos dessa afirmação:

Informamos que a pesquisa não the trará nenhum ônus e que você tem a liberdade para participar ou não, sendo-lhe reservado o direito de desistir da mesma no momento em que desejar, sem que isto the acarrete qualquer prejuizo. Informamos também que não haverá divulgação personalizada das informações, que você não receberá qualquer espécie de reembolso ou gratificação devido à participação neste estudo e que terá o direito a uma via do Termo de Consentimento Livre e Esclarecido (CECATTO, 2013, p. 170).

Em muitos momentos, os profissionais se emocionaram, choraram, silenciavam, analisavam suas falas, tornando-se importante nessas ocasiões a confiança depositada na pesquisadora e a manutenção da privacidade e da ética em relação às questões narradas (MACHADO, 2013, p. 30).

Para manter sua privacidade e anonimato, seu nome não será utilizado. Essa pesquisa se propõe a beneficiar a área de formação de professores para atuar na EaD, e não representa riscos aos participantes. Qualquer informação adicional ou esclarecimentos acerca deste estudo poderão ser obtidos junto à pesquisadora responsável [...] (PEREIRA, 2013, p. 106).

Os participantes terão mantido o seu anonimato em citações nesta investigação e em outras dela decorrentes. Informamos também que não haverá qualquer espécie de remuneração ou reembolso em virtude da sua participação (MENEZES, 2012, p. 137)

É fundamental que as questões sejam respondidas com honestidade e com a certeza de que sua privacidade está garantida, ou seja, o seu nome não será citado em momento algum desta pesquisa (VIANA, 2013, p. 173).

Os critérios de seleção dos sujeitos, levados em consideração ao longo da pesquisa, foram: que fossem alunos dos cursos de licenciatura em Filosofia e em Ciências Sociais da UECE e, portanto, pertencentes às turmas a serem pesquisadas; que tivessem interesse, voluntariamente, de participar da pesquisa; e que assinassem o termo de consentimento de livre esclarecido para que pudessem ser utilizado (sic) na pesquisa (este documento é prescrito pelo Comitê de Ética da Universidade) (OLIVEIRA-SILVA, 2013, p. 66).

Outra verificação do estudo, e essa talvez a mais latente, é que 4 dissertações (17\%) que trabalharam com sujeitos não apresentaram nenhum procedimento ético (CAVALCANTE FILHO, 2013; ROCHA, C., 2013; ROCHA, S., 2013; MARTINS, 2013). O detalhe é que os quatro pesquisadores trabalharam com a metodologia de estudo de caso, mas não mencionaram os procedimentos éticos que adotaram na pesquisa. Apenas uma pesquisa informa sobre o respeito e a dignidade dos sujeitos pedindo a colaboração quanto às respostas do questionário e, na sequência, quanto ao consentimento da entrevista:

\begin{abstract}
Gostariamos de contar com a colaboração de vocês, solicitando que respondam a três perguntas [...] Gostaria de agradecê-lo (la) pela disposição em colaborar conosco. O objetivo aqui é conversar sobre esta experiência, que, com sua anuência, gostariamos de gravá-la em áudio (MARTINS, 2013, p. 121-122).
\end{abstract}

A pesquisa mostra que apenas 2 (8\%) pesquisadores tiveram o cuidado de se aproximar da legislação ética com mais detalhes (ROCHA, S., 2013; REIS 2013). O primeiro trabalho define que "a metodologia adotada assentou-se no paradigma interpretativo, utilizando métodos mistos de pesquisa. Envolveu técnicas qualitativas (entrevista e pesquisa documental) e quantitativa (survey online)" (ROCHA, S., 2013, p. 15).

Além do respeito à dignidade humana, na sequência, verifica-se no trabalho de Rocha, $\mathrm{S}$. (2013) a discussão sobre os riscos e os benefícios da pesquisa. Notamos que a pesquisadora afirma que "não haverá riscos" para os sujeitos e que os beneficios são para a pesquisa, não sendo mencionado nada em relação aos sujeitos e nem sobre a liberdade de desistência a qualquer momento da pesquisa. Vejamos como ela se posiciona:

A coleta de dados será realizada por meio de aplicação de questionário (survey online). As informações coletadas serão utilizadas exclusivamente para fins de pesquisa científico 
acadêmica e serão tratadas coletivamente, de forma sigilosa, de forma que a sua identidade não será revelada nos resultados do estudo. Não haverá riscos, sendo que o benefício esperado será contribuir para melhoria da qualidade na formação de tutores (ROCHA, S., 2013, p. 197).

O segundo trabalho que mais se aproximou das exigências legais da ética em pesquisa com seres humanos foi o de Reis (2013). A pesquisadora, partindo do método histórico-cultural, evidencia em sua pesquisa a dignidade e o respeito aos seres humanos quanto à privacidade e ao anonimato, ao correto uso do TCLE, à liberdade de desistência e aos riscos da pesquisa, e conclui dizendo: "desde já, agradeço a sua participação, reiterando o caráter confidencial de suas informações" (REIS, 2013, p. 136). Entretanto, a única falha ética foi não ter mencionado os benefícios para a pesquisa e para os sujeitos.

Por fim, quanto aos riscos e aos benefícios da pesquisa, apenas 3 (12\%) trabalhos fazem essa discussão (CECATTO, 2013; PEREIRA, 2013; VIANA, 2013). Cecatto (2013, p. 171) informa sobre essa possibilidade no TCLE, mas não está claro no texto quais riscos seriam esses. Verificamos que, dentre os três autores que tratam dos riscos e dos benefícios, somente uma afirma que eles são "mínimos" (MENEZES, 2013). Outra autora fala do benefício de sua pesquisa para a área, mas não para os sujeitos (PEREIRA, 2013). A terceira pesquisadora não fala dos benefícios diretamente, mas que a participação dos sujeitos não lhes "trará prejuizo" (VIANA, 2013, p. 176).

Garantimos que os riscos ao participar desta pesquisa serão mínimos, uma vez que, seus dados pessoais serão preservados em sigilo, tendo acesso a estes somente as pesquisadoras deste estudo, e que só serão divulgados em eventos e periódicos científicos dados diretamente relacionados aos objetivos da pesquisa. O questionário poderá causar constrangimentos aos participantes. Evidenciamos, no entanto, que ao participar deste estudo você estará contribuindo para a melhoria da formação dos profissionais da Educação (MENEZES, 2013, p. 165).

Essa pesquisa se propõe a beneficiar a área de formação de professores para atuar na EaD, e não representa riscos aos participantes [...] (PEREIRA, 2013, p. 106).

Garante-se que a pesquisa não trará prejuizo na qualidade e condições de vida dos partici- pantes, salientando que as informações serão sigilosas, e que não haverá divulgação personalizada das informações (VIANA, 2013, p. 176).

Em suma, por meio das análises das dissertações de 2013, percebemos que $25 \%$ dos trabalhos são teóricos e, por isso, não tiveram a preocupação com a ética. Dos trabalhos que tiveram seres humanos como sujeitos, $42 \%$ apresentam certo cuidado com a ética, sendo que a grande ênfase está na dignidade e no respeito aos seres humanos e no uso do TCLE. O achado mais curioso foi que $17 \%$ das dissertações que trabalharam com sujeitos, sobretudo na metodologia de estudo de caso, não apresentaram nenhum procedimento ético. Neste contexto, apenas $8 \%$ dos pesquisadores se aproximaram da legislação ética com mais atenção.

\subsection{As dissertações defendidas no ano de 2014}

Observamos no conjunto das dissertações de 2014, que 7 (27\%) são estudos teóricos que nem sequer mencionaram alguma preocupação ética em seus trabalhos. Essa constatação é interessante, até para refletirmos sobre o que os mestrandos do PPGE/UECE de 2014 entendem por procedimentos éticos, já que o uso da ética não deve ser acionado e/ou lembrado apenas quando as pesquisas envolvem os sujeitos externos aos trabalhos acadêmicos. Pelo contrário, a busca deve almejar o ser ético, ou seja, uma postura que deve estar entranhada em todo ser humano. Dessa forma, a postura ética deve primeiramente estar aderida ao ser do pesquisador, pois, somente assim, evitaremos que trabalhos essencialmente teóricos não caiam nas armadilhas antiéticas do plágio ou do falseamento de dados de pesquisas, fatos que infelizmente acontecem, mas que precisam ser combatidos.

Percebemos que 19 dissertações (73\%) defendidas nesse mesmo ano preocuparamse com a questão dos princípios de dignidade e de respeito aos seres humanos, tanto que os mestrandos do PPGE/UECE ressaltaram esse item de forma incisiva em seus escritos:

No que concerne aos procedimentos éticos, nossa preocupação centrou-se em proteger os sujeitos envolvidos de danos físicos e psicológi- 
cos, e a velar para que seus direitos não sejam violados. Além disso, a investigação contou com a aprovação do Comitê de Ética em Pesquisa (Plataforma Brasil), em 24 de agosto de 2013. com o Parecer $n^{\circ} 370.505$ que avaliou tanto os aspectos éticos quanto os metodológicos [...] Importa destacar que esta pesquisa congregou os referencias preconizados na Resolução nº 466/2012 do Conselho Nacional de Saúde, indicado para estudos que envolvem seres humanos. Portanto, nos comprometemos em garantir o anonimato dos sujeitos e das instituições de ensino onde realizamos as entrevistas e observações. Para cumprir com esse anonimato, estabelecemos nomenclaturas para cada sujeito e escola, a fim de melhor identificar os dados no momento da organização e análise do material (NUNES, 2014, p. 105).

A pesquisa contou com a aprovação do Comitê de Ética e Pesquisa da UECE, por meio do parecer $n^{\circ}$ 356.808 (ANEXO C) e do HUUFMA com parecer $n^{\circ} 31 / 2013$ (ANEXO D) para avaliar os aspectos técnicos e metodológicos (RABELO, 2014, p. 35).

Pelo exposto, a grande maioria seguiu o princípio ético da dignidade e do respeito, e a escrita dos autores obedecia a certo padrão: "para escolha das egressas e garantia do anonimato, classificou-se como EV (Egressa Voluntária) e EB (Egressa bolsista) (RABELO, 2014, p. 33), porém somente Nunes (2014) especifica que submeteu seu trabalho ao Comitê de Ética em Pesquisa (Plataforma Brasil), do qual obteve resposta positiva em relação à avaliação dos aspectos éticos e metodológicos. Outro destaque interessante é a aprovação do estudo de Rabelo (2014) pelo Comitê de Ética em Pesquisa do Hospital Universitário da Universidade Federal do Maranhão (HUUFMA), único trabalho com temática que envolve a formação do pedagogo e o espaço hospitalar como lugar não formal de educação.

Os princípios da autonomia e da liberdade de desistência da pesquisa foram sumariamente ignorados em 15 estudos (60\%), o que soa contraditório na escrita dos pesquisadores, já que entendemos que dignidade e respeito implicam também em proporcionar liberdade de permanência e/ou desistência aos sujeitos envolvidos. Percebe-se que não adianta termos posturas éticas pela metade, pelo contrário, envolver indivíduos implica redobrarmos esse cuidado ético do início ao fim da pesquisa.

No que se refere aos aspectos legais, item beneficios, Ferreira (2014, p. 91) afirma que "a leitura do Termo de Consentimento Livre e Esclarecido - TCLE para lembrar o professor acerca dos objetivos da pesquisa e da sua participação", apenas esclarece os ganhos para os envolvidos em sua pesquisa de forma superficial. Porém, ao aprofundarmos nossa investigação, constatamos que no parecer do Comitê de Ética da UECE, anexo ao seu trabalho, ao contrário do que se esperava, o autor evidencia os benefícios que a pesquisa proporcionará aos sujeitos.

Continuando com os aspectos legais que prezam para que os riscos sejam devidamente esclarecidos e alertados, 7 trabalhos (27\%) seguem com o cuidado de especificar que suas pesquisas não oferecem danos físicos nem psicológicos aos sujeitos, desde que os procedimentos éticos sejam corretamente aplicados aos sujeitos participantes.

Além de divulgados os objetivos deste instrumento para os sujeitos, realçaram-se como necessário os procedimentos éticos, para que não houvesse nenhum dano fisico ou psicológico ao sujeito pesquisado, bem como a preservação de seus direitos (RABELO, 2014, p. 35).

Consideramos que, simplesmente, ignorar os riscos, mesmo que eles sejam quase que inexistentes, não reflete uma postura ética comprometida com o ser humano. Acreditamos que se faz necessário sempre estar em alerta, afinal, não sabemos como mensurar o impacto dessas pesquisas, por isso, não convém agirmos com parcimônia ética.

Por último, no que concerne ao TCLE, muitos mencionam especial atenção a esse documento, mas somente 7 estudos (27\%) de fato o anexam e justificam sua utilização, a exemplo de Nunes (2014, p. 105):

Deste modo, após essa aprovação, entramos em campo, tomando alguns procedimentos éticose deontológicos, como a apresentação do Termo de Consentimento Livre e Esclarecido, dirigido aos sujeitos participantes da pesquisa, para a autorização da utilização de suas informações por meio de gravação emáudio. (NUNES, 2014, p. 105).

Consideramos grave esse achado da pesquisa. Sabemos que o TCLE é imprescindivel, afinal, como avançar com os procedimentos éticos sem 
a sua utilização no começo da pesquisa? Fica o alerta para que possamos voltar o nosso olhar com mais propriedade para as questões éticas que permeiam os trabalhos que envolvem sujeitos.

\subsection{As dissertações defendidas no ano de 2015}

Os trabalhos de pesquisa de mestrado do ano de 2015, no que diz respeito aos estudos com humanos, apontam para uma ênfase na dignidade e no respeito aos seres humanos quanto ao respeito e ao anonimato, à liberdade de desistência a qualquer momento da pesquisa e ao uso do TCLE. Não houve cuidado ético adequado quanto aos benefícios e aos riscos claros da pesquisa (Quadro 1).

Quanto à dignidade e ao respeito para com os seres humanos, alguns sujeitos assim se posicionam no trato com os sujeitos:

Sua participação é voluntária e se dará por meio do preenchimento de questionário eletrônico a ser respondido on-line e da realização de entrevista semiestrutura (sic.). Se você aceitar participar, estará contribuindo para o desenvolvimento dos estudos sobre a política pública de formação de professores no âmbito do PIBID (ANJOS, 2015, p. 116).

Ficaram claros para mim quais são os objetivos e a que esta pesquisa se destina, bem como os procedimentos a serem realizados, as garantias de confidencialidade e de esclarecimentos permanentes e, ainda que minha participação será isenta de despesas e que poderei retirar o meu consentimento a qualquer momento, antes ou durante o mesmo, sem penalidades ou prejuizo (LIMA, 2015, p. 152).

Verificamos na fala de Anjos (2015) o fundamento do trabalho da pesquisa que é a adesão voluntária do sujeito à pesquisa. O respeito ético do pesquisador é fundamental para o tratamento do ser humano como sujeito de vontades e não como objeto de escrutínio científico. Nessa direção, outros dois trabalhos ratificam esse princípio ético: "levando em consideração questões éticas da pesquisa, mantivemos a identidade dos sujeitos pesquisados em sigilo, sendo identificados por códigos no texto" (BORGES, 2015, p. 69) e "[...] todas as informações coletadas neste estudo são estritamente confidenciais. Na publicação dos resultados desta pesquisa, sua identidade será mantida no mais rigoroso sigilo. Serão omitidas todas as informações que permitam identificá-lo (a)" (SILVA, 2015, p. 130).

No tocante à autonomia e à liberdade de desistência da pesquisa, destacamos três autoras, das quais duas já foram mencionadas anteriormente, Anjos (2015) e Borges (2015):

Se depois de consentir em sua participação o Sr.(a) desistir de continuar participando, tem o direito e a liberdade de retirar seu consentimento em qualquer fase da pesquisa, seja antes ou depois da coleta dos dados, independente do motivo e sem nenhum prejuizo a sua pessoa (ANJOS, 2015, p. 116).

Se depois de consentir em sua participação o Sr.(a) desistir de continuar participando, tem o direito e a liberdade de retirar seu consentimento em qualquer fase da pesquisa, seja antes ou depois da coleta dos dados, independente do motivo e sem nenhum prejuizo a sua pessoa (BORGES, 2015, p. 108).

Informamos que mesmo após consentir a participação na pesquisa a Sra. tem o direito e liberdade de retirar seu consentimento a qualquer momento, sem nenhum prejuizo a sua pessoa (SILVA, 2015, p. 156).

Percebemos que a ideia do direito e da liberdade de desistência sem prejuizos é uma tônica nas posições das três pesquisadoras. Notamos, porém, que Anjos (2015) e Borges (2015) são textualmente iguais. Inferimos desse dado que os protocolos éticos de pesquisa em educação vão assumindo certo padrão, sobretudo, no que diz respeito à elaboração do TCLE, no qual essas informações geralmente estão disponiveis:

Para o devido desenvolvimento desta investigação seguimos as normas éticas estabelecidas pela Resolução n 466/12 do Conselho Nacional de Saúde aprova as diretrizes e normas regulamentadoras de pesquisas envolvendo seres humanos. [...] Neste sentido, todos os dados foram tratados com o rigor ético necessário. (SILVA, 2015, p. 68).

Em relação aos aspectos legais, Silva, D. (2015) evidencia seu cuidado com todos os outros elementos que já viemos discutindo, acrescentando o correto uso do TCLE, tratando dos riscos e dos benefícios da pesquisa. Em relação aos riscos, deixa claro para seus sujeitos "[...] que a participação nesta pesquisa não traz complicações legais. Nenhum 
dos procedimentos usados oferece riscos à sua dignidade" (SILVA, 2015, p. 129).

Entretanto, essa autora apresenta os benefícios apenas para a pesquisa e não para os sujeitos: "[...] espera-se que o estudo possibilite informações importantes sobre a complexidade das práticas de leitura vivenciadas pelo professor e sua relação com o trabalho docente cotidiano" (SILVA, 2015. p. 130). Ainda sobre os benefícios, outro autor também segue uma linha de pensamento que caminha em uma dimensão hipotética, deixando a entender que os benefícios poderiam atingir diretamente a pesquisa sobre formação de professores e indiretamente os sujeitos investigados e seus pares:

Acredita-se que as informações obtidas neste estudo possam ajudar a aprofundar as reflexões acerca do papel e da importância de docentes da Educação Básica no processo formativo de novos professores, dada a sua experiência profissional e a oportunidade de confrontação teórico-prática (SILVA, 2015, p. 158).

Perfazendo os aspectos legais, considerando que em 2015 temos 5 dissertações (19\%) teóricas e 21 (81\%) que tiveram pesquisas com seres humanos, apenas 13 fizeram uso do TCLE. Desse grupo, é possivel destacar autores que reconhecem a importância desse instrumento, não só como uma condução assertiva técnica em suas pesquisas, mas de se ter a certeza de que, ao utilizarem o TCLE, estão demonstrando profundo respeito aos sujeitos entrevistados.

Um deles, ao ser solicitado a colaborar com este estudo (durante a assinatura do Termo de Consentimento Livre e Esclarecido), ainda interpelou: "mas, por que você está fazendo essa pesquisa? Aonde esses resultados serão apresentados? Eu fico muito preocupado em falar coisas que serão publicadas por aí! De repente... nunca se sabe". A isto foi necessário responder, retomando o próprio termo, apresentando e reafirmando o compromisso de realização da pesquisa, segundo normas éticas de preservação dos sujeitos colaboradores. Após tal esclarecimento, o professor dissipou sua suspeita e declarou estar feliz com o fato de que alguém quisesse abordar numa pesquisa de mestrado o PIBID daquela licenciatura (SILVA, 2015, p. 47).

Silva (2015) evidencia esse aspecto do respeito aos entrevistados ao decidir reler o seu TCLE, reconhecendo que é preciso deixar os sujeitos seguros quando a garantia de sua integridade física e psicológica. Infelizmente constatamos que nem todos pensam dessa forma. Outro destaque interessante está presente na pesquisa de Farias (2015, p. 35) quando diz que "o estudo seguiu o que preceitua a Resolução de n. ${ }^{\circ}$ 466/2012, fazendo-se uso, em todas as entrevistas, do Termo de Consentimento e Livre Esclarecido (TCLE)", nesse caso, somente Farias (2015) fez menção à Resolução n. ${ }^{\circ}$ 466/2012. Tal fato pode ser um indicativo de desconhecimento do conteúdo e da importância desse documento no tocante à condução dos procedimentos éticos nas pesquisas de mestrado desse mesmo ano.

Sendo assim, verificamos que 8 trabalhos (31\%) não apresentam esse documento em anexo nas suas pesquisas. Essa é uma questão delicada do ponto de vista científico, pois revela que os procedimentos éticos nas pesquisas de mestrado não estão adequados para atender às Resoluções n. ${ }^{\circ} 166 / 96$ e n. ${ }^{\circ} 510 / 2016$.

\section{Achados de pesquisa e considerações finais}

A investigação científica não tem em si mesma o crivo ético para (re)definir seu modus operandi, seja para alienar ou para emancipar. O ser humano vive diariamente com a possibilidade da transgressão, e é isso que o faz ético, em sua existência como pessoa e/ou como pesquisador. Sendo assim, retomando o nosso problema de pesquisa, "como as pesquisas de mestrado em educação vêm desenvolvendo a ética na pesquisa científica no âmbito da universidade?", teceremos a seguir comentários sobre a análise dos dados.

De maneira geral, os achados apontaram surpresas! Estávamos com a convicção de que nos depararíamos com dissertações que materializariam a importância da ética, tanto nas pesquisas envolvendo sujeitos, bem como dos estudos essencialmente teóricos, no entanto, percebemos a instauração de um cenário controverso.

A principal contradição refere-se à valorização e à referência à dignidade e ao anonimato dos sujeitos por parte dos mestrandos, porém algumas lacunas procedimentais, como a falta de documentação básica anexada como TCLE, 
a não menção sobre a liberdade para que os envolvidos pudessem desistir, os equivocos quanto aos esclarecimentos de quais são, de fato, os riscos e os benefícios e como eles devem ser comunicados aos sujeitos partícipes nos põem em reflexão sobre como o Mestrado em Educação do PPGE/UECE tem trabalhado seus procedimentos éticos no campo da pesquisa

A pesquisa em tom de revisão de bibliografia apontou que as dissertações de mestrado em educação do PPGE/UECE de 2013 a 2015 valorizam a dignidade e o respeito aos seres humanos. Entretanto, faz-se necessário fortalecer a formação ética dos pós-graduandos, de tal forma que ela seja assinalada desde a concepção e a execução do projeto até a elaboração do relatório da pesquisa. Além disso, é importante que os trabalhos com seres humanos pautem suas posturas com clareza junto aos sujeitos, deixando claro quais os possiveis riscos e benefícios para esses, bem como as contribuições da pesquisa em curso para a área de investigação.

Deixamos uma palavra para os estudos teóricos que não envolvem sujeitos. A grande armadilha desses trabalhos reside na tentação do plágio e do autoplágio. Faz sentido pensar que o orientador dos mestrandos tem um papel formativo fundamental neste processo de elaboração e de produção das pesquisas de dissertação unicamente teóricas, mas acima de tudo que seja resultado da singularidade e da originalidade dos educandos, pesquisadores em formação.

\section{Referências}

ALVES, Alda Judith. A "revisão da bibliografia" em teses de dissertações: meus tipos inesqueciveis. Cadernos de Pesquisa. São Paulo, n. 81, p. 53-60, maio 1992.

ALVES, Rubem. Conversas com quem gosta de ensinar. 7. ed. Campinas, SP: Papirus, 2000.

ANJOS, Ana Maura Tavares dos. Reflexividade e formação continuada de professores no âmbito do PIBID: evidências de contribuições para o desenvolvimento profissional de docentes da educação básica. 2015. 122f. Dissertação (Mestrado em Educação) - Universidade Estadual do Ceará, Fortaleza, 2015. https://doi.org/10.17771/pucrio.acad.12032.
ARAÚJO, Adéle Cristina Braga. Estética em Lukács: reverberações da arte no campo da formação humana. 2013. 115f. Dissertação (Mestrado em Educação) Universidade Estadual do Ceará, Fortaleza, 2013.

BERNARDO, Érico Costa. Política pública de esporte no contexto dos megaeventos esportivos: a cidade de Fortaleza em cena. 2013. 163f. Dissertação (Mestrado em Educação) - Universidade Estadual do Ceará, Fortaleza, 2013. https://doi.org/10.5327/ z1806-3144201700030006.

BEZERRA, Martha Maria Macedo. De aluno a professor formação docente de egressos da Escola Normal Rural de Juazeiro do Norte-Ce. 2013. $123 \mathrm{f}$. Dissertação (Mestrado em Educação) - Universidade Estadual do Ceará, Fortaleza, 2013. https://doi. org/10.1590/s1516-73132013000300011.

BORGES, Caroline Teixeira. O professor supervisor do PIBID: o que pensa, faz e aprende sobre a profissão? 2015. 110f. Dissertação (Mestrado em Educação) - Universidade Estadual do Ceará, Fortaleza, 2015.

BOUFLEUER, José Pedro. Pedagogia da ação comunicativa: uma leitura de Habermas. 3. ed. Ijuí: Editora Unijuí, 2001.

BRASIL. Lei de Diretrizes e Bases da Educação Nacional n. 9394/96. Brasília, 1996.

BRASIL. CONSELHO NACIONAL DE SAÚDE. Resolução n ${ }^{196}$, de 10 de outubro de 1996. Brasilia, 1996.

BRASIL. CONSELHO NACIONAL DE SAÚDE. Resolução $n^{\circ}$ 466, de 12 de dezembro de 2012. Brasília, 2016.

BRASIL. CONSELHO NACIONAL DE SAÚDE. Resolução n $^{\circ}$ 510, de 7 de abril de 2016. Brasília, 2016.

CAVALCANTE FILHO, Antônio. Significações dos docentes sobre a educação infantil: viajando através do reino mítico dos contos de fada e seus símbolos. 2013. 156f. Dissertação (Mestrado em Educação) Universidade Estadual do Ceará, Fortaleza, 2013. https://doi.org/10.12957/teias.2018.34010.

CECATTO, Adriano. O ensino do uso de imagem na formação de professores de História. (Mestrado em Educação). 2013. 175f. Dissertação (Mestrado em Educação) - Universidade Estadual do Ceará, Fortaleza, 2013. https://doi.org/10.11606/t.48.2019.tde-14052019-123037.

CRESWELL, John W. Projeto de pesquisa: métodos qualitativo, quantitativo e misto. 2. ed. Porto Alegre: Artmed, 2007. https://doi.org/10.26512/les.v13i1.11610.

FARIAS, Maria A. Avaliação externa e gestão da escola: apropriações e usos dos dados do IDEB na gestão de escolas públicas municipais de fortaleza. 2015. 227f. Dissertação (Mestrado em Educação) Universidade Estadual do Ceará, Fortaleza, 2015. https://doi.org/10.17771/pucrio.acad.23584.

FERREIRA, Maria Nahir B. A formação docente e a constituição dos saberes dos professores de história de Icó - Ce. 2014. 170f. Dissertação (Mestrado em Educação) - Universidade Estadual do Ceará, Fortaleza, 2014 
FREIRE, Paulo. Pedagogia da autonomia: saberes necessários à prática educativa. 34.ed. São Paulo: Paz e Terra,1996. https://doi.org/10.18764/24466549.2019.10355.

GOERGEN, Pedro Laudinor. A ética em pesquisa. Revista Práxis Educativa, Ponta Grossa, Ahead of print, v. 10, n. 2, jul./dez. 2015, pp. 301-315. https:// doi.org/10.5212/praxeduc.v.10i2.0001.

GUBA, Egon G.; LINCOLN, Yvonna. S. Competing paradigms in qualitative research. In: DENZIN, N. K.; LINCOLN, Y. S. (ed.). Handbook of qualitative research. Thousand Oaks/California: SAGE, 1994. p. 105-117. https://doi.org/10.1177/1468794114560856.

HABERMAS, Jurgen. Técnica e ciência como ideologia. Edições 70: Lisboa, 1968

LA FARE, Mónica de la; MACHADO, Frederico Viana; CARVALHO, Isabel Cristina de Moura. Breve revisão sobre regulação da ética em pesquisa: subsídios para pensar a pesquisa em educação no Brasil. Revista Práxis Educativa, Ponta Grossa, v. 9, n. 1 , p. 247-283, jan./jun. 2014, p. 247-283. https://doi. org/10.5212/praxeduc.v. gi1.0012.

LIMA, Cristiane Maria Abreu. A opressão contra mulher e a educação: uma análise classista do discurso do capital. 2013. 93f. Dissertação (Mestrado em Educação) - Universidade Estadual do Ceará, Fortaleza, 2013. https://doi.org/10.20873/ uft.2525-4863.2017v2n1p294.

LIMA, Gercilene Oliveira de. Estágio curricular supervisionado para alunos que já exercem o magistério: possibilidades de ressignificação dos saberes docentes? 2015. 153f. Dissertação (Mestrado em Educação) - Universidade Estadual do Ceará, Fortaleza, 2015. https://doi.org/10.17648/cied-2018-91543.

MACHADO, Cláudia Rodrigues. Desenvolvimento profissional de egressos da pedagogia do CEClTEC: caminhos da profissão. 2013. 142f. Dissertação (Mestrado em Educação) - Universidade Estadual do Ceará, Fortaleza, 2013.

MARTINS, Maria Márcia Melo de Castro. Estágio de docência na pós-graduação stricto sensu: uma perspectiva de formação pedagógica. 2013. $137 f$. Dissertação (Mestrado em Educação) - Universidade Estadual do Ceará, Fortaleza, 2013. https://doi. org/10.17524/repec.v4i2.202.

MENEZES, lany Bessa Silva. Formação continuada de professores no município de Caucaia: entre a formação e a prática do ensino de arte na educação infantil. 2013. 172f. Dissertação (Mestrado em Educação) - Universidade Estadual do Ceará, Fortaleza, 2013. https://doi.org/10.17771/pucrio.acad.12032.

NUNES, Camila A. A formação continuada do docente para atuar na perspectiva da inclusão: a busca de contribuições para a prática pedagógica do professor da escola regular. 2014. 163f. Dissertação (Mestrado em Educação) - Universidade Estadual do Ceará, Fortaleza, 2014. https://doi. org/10.31692/2358-9728.iiicointerpdvl.2016.00029.
OLIVEIRA, Manfredo de. Conhecimento e historicidade. In: Tópicos sobre dialética. Editora EdPUCRS: Rio Grande do Sul, 1997, p. 9-41.

OLIVEIRA-SILVA, Geraldo Magela. Cinema e formação de professores em cursos de licenciatura. Programa de Pós-graduação em Educação. 2013. 126f. Dissertação (Mestrado em Educação) - Universidade Estadual do Ceará, Fortaleza, 2013. https:// doi.org/10.20873/uft.rbec.e7334.

PEREIRA, Elane Silva. Formação e prática do professor autor na EaD: elaboração de material didático para o curso de pedagogia da UAB/UECE. 2013. $122 \mathrm{f}$ Dissertação (Mestrado em Educação) - Universidade Estadual do Ceará, Fortaleza, 2013. https://doi. org/10.1590/s1517-97022013000300013.

RABELO, Francy S. Educação não escolar e saberes docentes na formação do pedagogo: análise de uma experiência no espaço hospitalar. 2014. 184f. Dissertação (Mestrado em Educação) - Universidade Estadual do Ceará, Fortaleza, 2014. https://doi. org/10.11606/t.81.2013.tde-16052013-123729.

REIS, Francisca das Chagas Soares. Os sentidos e os significados atribuidos pelos professores ao processo de formação continuada: um estudo no Colégio Militar de Fortaleza. 2013. 144f. Dissertação (Mestrado em Educação) - Universidade Estadual do Ceará, Fortaleza, 2013. https://doi.org/10.5327/ z1679443520180167.

RIBEIRO, Renata Rosa Russo Pinheiro Costa. Formação de professores para a educação inclusiva no contexto da legislação dos documentos oficiais: quais as mudanças concorridas. 2013. 165f. Dissertação (Mestrado em Educação) - Universidade Estadual do Ceará, Fortaleza, 2013. https://doi. org/10.29388/978-85-53111-04-6-0-f.15-26.

$\mathrm{ROCHA}$, Sinara Socorro Duarte. Processo formativos e a constituição da docência on line: o universo paralelo de Alice. 2013. 209f. Dissertação (Mestrado em Educação) - Universidade Estadual do Ceará, Fortaleza, 2013

ROCHA, Silviane da Silva. Ser professor em EaD: saberes e prática no estágio supervisionado do curso de pedagogia UAB/UECE. 2013. 113f. Dissertação (Mestrado em Educação) - Universidade Estadual do Ceará, Fortaleza, 2013. https://doi.org/10.15411/figeea.v6io6.74.

ROCHA, Cláudio César Torquato. Saberes da docência aprendidos no PIBID: um estudo com futuros professores de sociologia. 2013. 163f. Dissertação (Mestrado em Educação) - Universidade Estadual do Ceará, Fortaleza, 2013. https://doi.org/10.5585/ dialogian13.2802.

SÁ-SILVA, Jackson R.; ALMEIDA, C. D.; GUINDANI, J. F. Pesquisa documental: pistas teóricas e metodológicas. Revista Brasileira de História e Ciências Sociais. São Leopoldo, v.1, n.1, p. 1-15, jul. 2009. Disponivel em: http://www.rbhcs.com/index_arquivos/ Artigo.Pesquisa\%20documental.pdf. Acesso em: 09 jan. 2010. https://doi.org/10.14295/rbhcs.v7i14.230.

SAVIANI, Dermeval. História das Ideias Pedagógicas no Brasil. 3.ed. rev., - Campinas, SP: Autores Associados, 2010 (Coleção Memória da Educação). 
SEVERINO, Antônio Joaquim. Metodologia do Trabalho Científico. 22. ed. rev. e ampl. de acordo com a ABNT. Sâo Paulo: Cortez, 2002.

SILVA, Daniele Cariolano da. A semiformação em Adorno e as práticas de leituras acadêmicas de professores supervisores do PIBID/FECLESC. 2015 135f. Dissertação (Mestrado em Educação) - Universidade Estadual do Ceará, Fortaleza, 2015. https:// doi.org/10.24849/j.geot.2015.135.08.

VIANA, Flávia Roldan. A teoria da atividade na análise de episódios de ensino de matemática para alunos com surdez. 2013. 176f. Dissertação (Mestrado em Educação) - Universidade Estadual do Ceará, Fortaleza, 2013. https://doi.org/10.17143/ciaed/xxiilciaed.2017.00049.

\section{Hamilton Perninck Vieira}

Doutor em Educação pela Universidade Estadual do Ceará (UECE, Fortaleza, CE, Brasil), professor da Secretaria Municipal de Educação (SME) em Fortaleza, CE, Brasil.

\section{Jacques Therrien}

Doutor em Educação pela Cornell University (CU, Ithacha, Nova York, USA), professor Titular (aposentado) da Universidade Federal do Ceará (UFC) e docente visitante do Programa de Pós-Graduação em Educação da Universidade Estadual do Ceará (PPGE-UECE) em Fortaleza, CE, Brasil.

\section{Wendel Alves de Medeiros}

Doutor em Educação pela Universidade Estadual do Ceará (UECE, Fortaleza, CE, Brasil), professor do Instituto Federal de Educação, Ciência e Tecnologia do Ceará (IFCE) em Fortaleza, CE, Brasil.

\section{Endereço para correspondência}

Hamilton Perninck Vieira

Secretaria Municipal de Educação de Fortaleza

Av. Desembargador Moreira, 2875

Dionísio Torres 60170-002

Fortaleza, CE, Brasil 